\title{
Chief complaints of patients seeking treatment for Periodontitis
}

\author{
Vishakha Grover ${ }^{1}$, Ranjan Malhotra², Anoop Kapoor ${ }^{3}$, Gagandeep Kaur ${ }^{4}$, Rose Kanwaljeet Kaur ${ }^{5}$, Jasjit \\ Kaur Sahota ${ }^{6}$
}

\begin{abstract}
${ }^{1}$ Professor, ${ }^{5}$ Senior Assistant Professor, Dr. HS Judge Institute of Dental Sciences, Chandigarh, Punjab, ${ }^{2}$ Professor \& HOD, ${ }^{6} \mathrm{PG}$ Student, National Dental College \& Hospital, Mohali, Punjab, ${ }^{3}$ Professor \& HOD, Shri Sukhmani Dental College \& Hospital, Dera Bassi, Punjab, ${ }^{4}$ Senior Lecturer, Dept. of Periodontics \& Oral Implantology, Genesis Institute of Dental Sciences \& Research, Ferozepur, Punjab
\end{abstract}

*Corresponding Author:

Email: vishakha_grover@rediffmail.com

\begin{abstract}
Aim: To determine and analyse the most common chief complaints associated with chronic periodontitis in patients suffering from periodontal disease in Derabassi, Punjab, India.

Materials and Methods: Dental records of 7680 patients were examined. Categorisation of all the subjects on the basis of periodontal diagnosis, age and gender was carried out. The various chief complaints reported at first visit were grouped into 3 major groups based on patient perception. A rank order was created based upon the frequency of chief complaints and number of chief complaints per subject and analysed.

Results: Out of total (20750) 13 chief complaints recorded, only 5 were considered periodontitis symptoms and the remaining chief complaints were related to esthetics/ dental emergencies according to patient perception. Periodontitis symptom, as chief complaint was maximum for age group 41-50 years and female category, and the difference observed was statistically highly significant.

Conclusion: Deposits, stains and bleeding gums were the first, second and the third most common chief complaints respectively in the study population and most of them were related to esthetics according to patient's perception. This information should be utilised for enhancing awareness in general public for early diagnosis and effective periodontal treatment in early stages of periodontitis.
\end{abstract}

Keywords: Awareness, Chief complaint, Early diagnosis, Periodontal diseases

\section{Introduction}

Periodontal diseases are a group of diseases that cause inflammation and destruction of the investing and supporting structures of the teeth. ${ }^{(1)}$ Periodontal diseases, including gingivitis and periodontitis, are among the most common chronic diseases. ${ }^{(2)}$ Periodontal disease, ever since the days of Hippocrates has crippled the survival of human dentition.

As a quiescent disease most of the time, periodontal disease presents mainly a chronic or asymptomatic chief complaint. ${ }^{(3,4)}$ In its most common form, periodontal disease generally is considered to be a painless process unless it reaches severe stages. For this reason, it often is overlooked by patients and dentists in early stages, especially when inflammation is not obvious.

Studies have suggested that early detection and treatment of periodontitis via screening is needed to improve periodontal health. ${ }^{(5,6,7)}$ However, despite advances in technology, knowledge and skills over the last few decades, epidemiological studies have indicated that prevalence rates are not reflective of the periodontal care delivered. In other words, most existing disease is left untreated. ${ }^{(8,9,10,11,12)}$

The epidemiology of periodontal disease is one of the most important challenges before the dental profession. Periodontal disease accounts for the greatest loss of teeth in India. ${ }^{(13)}$ Lack of public concern and general unawareness of the consequences of periodontal disease have contributed to its broad prevalence. ${ }^{(14)}$ Periodontal disease is so prevalent that the only possible solution to the problem is "Prevention". Prevention aspect of periodontics requires the active involvement of both dentist and patient. Early diagnosis and treatment are the same side of the coin and are therefore essential. The disease should be intercepted in the earliest stage possible to prevent irreversible damage.

Patient's input is an essential part of clinical management for example a comprehensive medical and dental history is a prerequisite for dental treatment. The opinion of patients may be central to decision making; e.g. prior to planning the prosthetic rehabilitation of the dentition. ${ }^{(15)}$ "Listen to your patient carefully, he might be telling you the diagnosis." Thus the focus of interest should be on the patient who has the disease and not simply on the disease itself.

The chief complaints of patients are considered significant because they help dentist to quickly assess what is important to the patient, as well as the patient's understanding of periodontal disease. Patient's chief complaints represent their immediate demands and may implicate their attitude towards periodontal treatment. By quickly and effectively eliminating chief complaints the dentists can strengthen rapport with their patients and greatly enhance patient's cooperation and treatment 
outcome. Compared with symptoms such as pain, tooth mobility, periodontal abscess and tooth migration which are found in severe stages of periodontal disease, attention to chief complaint can guide admitting triage, diagnosis and early treatment.

Patient's input is important for clinical diagnosis, which is provided by chief complaints reported by the patients and comprehensive medical and dental history. Most periodontal textbooks contain little information concerning the chief complaints of patients with periodontitis. Many patient education brochures describe periodontal symptoms, but little is known about the relative importance of the symptoms in the chief complaints of patients with periodontitis.

The present survey was planned to determine the most common chief complaints associated with periodontitis in patients suffering from periodontal disease and to analyse the same on the basis of patient's perception as observed in the rural areas adjacent to Derabassi, Punjab.

\section{Materials and Methods}

The dental records of 7680 patients consecutively treated in the post graduate Department of Periodontics and Oral Implantology, National Dental College, Derabassi in the year 2013, were examined to determine what chief complaints (CC) the patients reported at their first examination visit. A format was drawn to record the various chief complaints reported by subjects seeking treatment for periodontitis. This included the date of visit of patient, name, O.P.D no., gender of patient and CC's reported, along with the total no. of CC's and patient's perception about the CC's. CC's from subjects dental records were listed and recorded the number of times a $\mathrm{CC}$ was repeated among the subjects to determine the most common complaints.

Data Analysis: The study subjects ranged in age from $18-70$ years; the mean age being 48.7 years. The data of the study subjects were divided into various age group categories (Table 1). Similarly, the total population was categorised according to periodontal diagnosis and gender (Table 2). Total 13 chief complaints were listed from the previous dental records and rank order was created based upon the frequency of chief complaints and number of chief complaints per subject (Table 3 ). The various complaints were grouped into 3 major groups based on patient perception as chief complaints related to (i) periodontitis symptoms, (ii) esthetics and (iii) dental emergency.

\section{Results}

Data analysis for 7680 subjects revealed a total number of 20750 chief complaints. The average number of chief complaints per subject was 2.70 , and the largest number of chief complaints reported by single subject was 7. Percentage of subjects within each age group varied, with maximum number of subjects i.e. $33.7 \%$ in age group 41-50 years (Table 1). From total of 7680 subjects, chronic generalised periodontitis was prevalent among $75.3 \%$ of the subjects, while chronic localised periodontitis was found to be in $24.3 \%$ of the subjects and aggressive in $0.29 \%$.

Table 1: Distribution of study subjects according to age

\begin{tabular}{|c|c|c|}
\hline \multicolumn{3}{|c|}{$\begin{array}{c}\text { Number and percentage of subjects in each } \\
\text { group }\end{array}$} \\
\hline $\begin{array}{l}\text { Age group } \\
\text { (years) }\end{array}$ & $\begin{array}{c}\text { Number of } \\
\text { subjects }\end{array}$ & $\begin{array}{l}\text { Percentage } \\
\text { of subjects }\end{array}$ \\
\hline $18-21$ & 18 & 0.2 \\
\hline $21-30$ & 192 & 2.6 \\
\hline $31-40$ & 1784 & 23.3 \\
\hline $41-50$ & 2590 & 33.7 \\
\hline $51-60$ & 2135 & 27.7 \\
\hline $61-70$ & 961 & 12.5 \\
\hline Total & 7680 & 100 \\
\hline
\end{tabular}

Table 2: Distribution of subjects by periodontal diagnosis

\begin{tabular}{|l|c|c|c|}
\hline \multicolumn{1}{|c|}{ Number of subjects by periodontal diagnosis } \\
\hline & $\begin{array}{c}\text { Number } \\
\text { of } \\
\text { subjects }\end{array}$ & Males & Females \\
\hline $\begin{array}{l}\text { Chronic } \\
\text { Generalised } \\
\text { periodontitis }\end{array}$ & 5790 & 1953 & 3837 \\
\hline $\begin{array}{l}\text { Chronic Localised } \\
\text { periodontitis }\end{array}$ & 1867 & 737 & 1130 \\
\hline $\begin{array}{l}\text { Aggressive } \\
\text { periodontitis }\end{array}$ & 23 & 6 & 17 \\
\hline Total & 7680 & 2696 & 4984 \\
\hline
\end{tabular}

Table 3: Percentage distribution of subjects in different chief complaint groups Number of chief complaints reported and percentage of subjects with each chief complaint

\begin{tabular}{|l|c|c|c|c|c|}
\hline Chief complaint & $\begin{array}{c}\text { Number of } \\
\text { chief } \\
\text { complaints } \\
\text { reported }\end{array}$ & $\begin{array}{c}\text { \%o of } \\
\text { subjects } \\
\text { with each } \\
\text { chief } \\
\text { complaint }\end{array}$ & $\begin{array}{c}\text { Periodontitis } \\
\text { symptom }\end{array}$ & $\begin{array}{c}\text { Dental } \\
\text { emergency } \\
\text { related }\end{array}$ & $\begin{array}{c}\text { Esthetics } \\
\text { related }\end{array}$ \\
\hline Deposits & 4632 & 60.31 & & & + \\
\hline Stains & 3012 & 39.21 & & & + \\
\hline
\end{tabular}




\begin{tabular}{|l|c|c|c|c|c|}
\hline Bleeding gums & 2772 & 36.09 & + & & \\
\hline Attrition & 2592 & 33.75 & & & + \\
\hline Mobility & 1968 & 25.62 & + & & + \\
\hline Foul odour & 1908 & 24.84 & + & & + \\
\hline $\begin{array}{l}\text { Cervical } \\
\text { abrasion }\end{array}$ & 1092 & 14.21 & & & + \\
\hline Hypersensitivity & 1056 & 13.75 & + & & + \\
\hline Food impaction & 738 & 9.60 & & & + \\
\hline $\begin{array}{l}\text { Gingival } \\
\text { enlargement }\end{array}$ & 516 & 6.71 & + & & + \\
\hline Abscess & 144 & 1.87 & & + & + \\
\hline Peri-coronitis & 92 & 1.19 & & & + \\
\hline Any other & 128 & 2.96 & & & \\
\hline Total & 20750 & & & & \\
\hline
\end{tabular}

Out of a total of 5790 subjects 1953 males and 3837 females were diagnosed with chronic generalised periodontitis (Table 2). Chronic generalised, chronic localised and aggressive periodontitis was found to be statistically highly significant in females than males $(\mathrm{P}=<.0001)($ Graph 1).

Graph 1: Distribution of subjects according to periodontal diagnosis in males and females

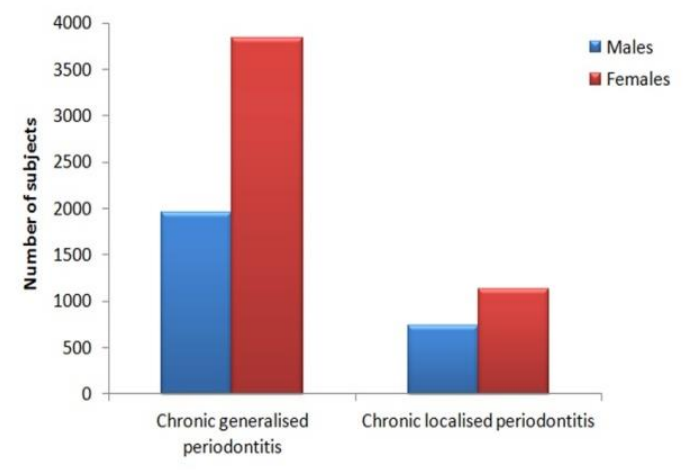

Number of chief complaints and \% of subjects with each chief complaint has been summarised in Table 3.Out of 13 chief complaints recorded only 5 were considered periodontitis symptoms and the remaining chief complaints were related to esthetics/ dental emergencies according to patient perception. Under periodontitis symptom category a total of 8218 chief complaints were recorded, where as for esthetic related category 17513 and for dental emergency related category 336 were the number of chief complaints recorded.

When analysed on the basis of gender periodontitis symptom as chief complaint were maximum for females i.e. 4679 as compared to 3539 for males, which was found to be highly significant $(\mathrm{P}=.00133)$, while esthetic related chief complaints for females were 10,021 as compared to 7492 for males and dental emergency related chief complaint was 221 for females and 115 for males (Table 4) (Graph 2).

Table 4: Distribution of total chief complaints according to age

\begin{tabular}{|l|c|c|c|}
\hline \multirow{2}{*}{ Gender } & \multicolumn{3}{|c|}{ Complaint group } \\
\cline { 2 - 4 } & $\begin{array}{c}\text { Esthetics } \\
\text { related }\end{array}$ & $\begin{array}{c}\text { Periodontitis } \\
\text { symptom }\end{array}$ & $\begin{array}{c}\text { Dental } \\
\text { emergency } \\
\text { related }\end{array}$ \\
\hline Females & 10,021 & 4679 & 221 \\
\hline Males & 7492 & 3539 & 115 \\
\hline
\end{tabular}

Table 5: Distribution of total chief complaints in different age categories

\begin{tabular}{|c|c|c|c|}
\hline \multirow{2}{*}{$\begin{array}{c}\text { Age } \\
\text { Group }\end{array}$} & \multicolumn{3}{|c|}{ Complaint Group } \\
\cline { 2 - 4 } & $\begin{array}{c}\text { Esthetics } \\
\text { related }\end{array}$ & $\begin{array}{c}\text { Periodontitis } \\
\text { symptom }\end{array}$ & $\begin{array}{c}\text { Dental } \\
\text { emergency } \\
\text { related }\end{array}$ \\
\hline $18-21$ & 94 & 43 & 1 \\
\hline $21-30$ & 187 & 1522 & 124 \\
\hline $31-40$ & 4642 & 1500 & 69 \\
\hline $41-50$ & 6574 & 2107 & 18 \\
\hline $51-60$ & 3087 & 1794 & 52 \\
\hline $61-70$ & 2929 & 1252 & 72 \\
\hline
\end{tabular}

Graph 2: Distribution of the chief complaints in male and female study population

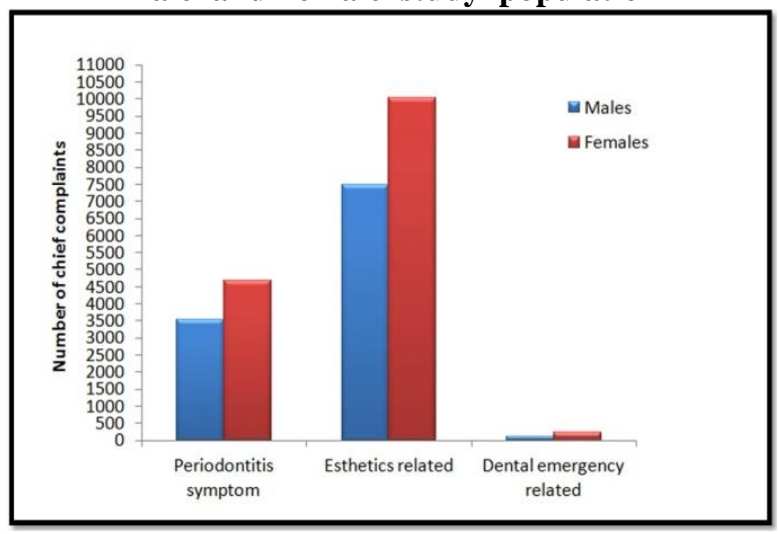


Categorisation on the basis of age revealed periodontitis symptom as chief complaint (2107) and esthetic related chief complaint (6574) was maximum for age group 41-50years and was highly significant for this age group $(\mathrm{P}=<.0001)$, while dental emergency related chief complaint(124) was highest for age group 21-30years (Table 5) (Graph 3).

\section{Graph 3: Distribution of chief complaints according} to various age groups

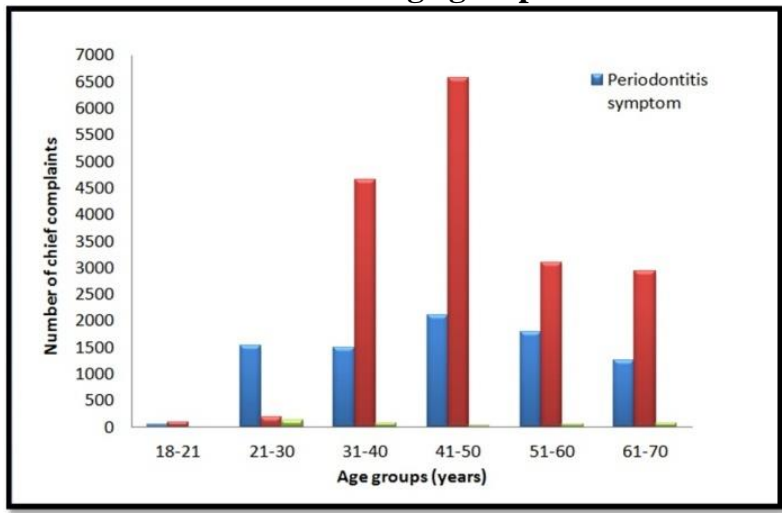

\section{Discussion}

Periodontitis is a slow, progressive, chronic inflammatory disease characterised by bursts of disease activity separated by quiescent periods of varying duration. ${ }^{(16,17)}$ Periodontal disease is mainly diagnosed at a chronic stage and usually the disease remains asymptomatic. Individually and collectively, the clinical symptoms of chronic gingivitis are rather vague, and usually painless. These features leave most patients unaware of the disease and are generally underestimated by the dental practitioners. In clinical practice, defining the objectives of therapy is a pivotal step in managing the patient. One of the significant factor in defining the objectives is patient's demands and profile. ${ }^{(18)}$ Patient's chief complaints (CC's), his perception, reasons and timing for seeking care can be valuable sources of information for the clinicians because these can significantly affect the patient's behaviour, attitude and willingness for the treatment.

In the present survey the first and the second most common chief complaints reported by the patients seeking treatment for periodontitis were "deposits and stains" which related to the esthetic concerns of the patients. It showed that rural patients were not really aware of the role of local deposits in the painless onset and progression of periodontal disease but took these as unsightly, affecting their appearance. The third most common chief complaint "bleeding gums" which was found to be the most common periodontitis symptom reported in this survey. The perception of patient about local deposits differed from bleeding as bleeding from a vital tissue associated with other clinical signs and symptoms was objective, more noticeable and visible to eyes and was supposed to be associated with some disease/pathology of the tissue. The fourth most common chief complaint came out to be "attrition" which also related to esthetics and fifth being "mobility" which was thought to be a periodontits symptom. Findings from our survey did not support the nation wide survey conducted in 1993 and survey conducted by Brunsvold MA et al in $1999^{(2)}$ in the graduate division of the Department of Periodontics at The University of Texas Health Science Center at San Antonio which suggested the most common CC reported was information given to subjects about their periodontal disease by a member of dental health team, most commonly a general dentist or dental hygienist. Both these studies emphasized that unless patients were informed that they have periodontal disease, many will not seek treatment.

Maximum patients seeking treatment for periodontitis were present in age group from 41-50 years $(33.7 \%)$ which correlated with the fact that the prevalence of periodontal disease is high in this age group. ${ }^{(19)}$ There was a significant difference between females and males as regard to the number and type of chief complaints. Greater number of females reported chief complaint in all the three complaint groups showed their more concern towards their own self, their health and hygiene.

Though the findings of the present survey differed from the previous studies but all are sure suggestive of the fact that painless or quiet initial phase of disease leads to the patient, not knowing about his present disease status, usually leads to delay in seeking the treatment at a progressed stage of disease and thus leaving more costly and less viable treatment options for the management. Although patient motivation and instruction is a painstaking procedure that requires patient's participation and careful supervision with correction of mistakes, plays a pivotal role in prevention of periodontal disease.

Patient's perception how they relate the very first sign of disease i.e. change from health to disability in function or just a cosmetic concern is also an important determinant for the patient's behaviour to seek treatment.

This survey furnishes the background data to get insight into the status of awareness of the patient suffering from periodontitis in the rural area of district Mohali, Punjab. The clinical implication of this survey was to emphasize on the most common chief complaint of patients with chronic nature of periodontal disease and to utilise this information for enhancing awareness in general public for early diagnosis and effective periodontal treatment in early stages of periodontitis.

It is seen that people are unable to recognize whether they are affected by dental and periodontal disease. Trevonen et alreported that people tend to underestimate their dental treatment needs, mainly in the field of periodontology. ${ }^{(20)} \mathrm{A}$ periodontal 
examination by general dentist once or thrice a year reveals any incipient or progressive problems. A full mouth series of X-ray is advised every 3-5years. ${ }^{(21)}$ This will alert the dentist to early bone loss and other disorders of oral cavity. Dentists now often perform Periodontal Screening and Recording (PSR) using a probe to measure pockets. This can be performed by the general dentist as a part of routine dental examination. The inputs from the patients could be used to improve the compliance of patient with particular concern being addressed and to improve periodontal treatment outcomes. Also informing and motivating the people lies in the hands of the professionals as well as the public health authorities. Professional examination and diagnosis should be more cognizant of the public perception, and professionals should be more involved regarding public dental health.

Prevention of periodontal disease requires the responsible action on the part of the individuals themselves, government and the society. Consumers and providers of health services have to become involved and there must be improved access to comprehensive care.

Overall, very less number of symptoms recorded as periodontitis symptoms showed the influence of the background characteristic of the regional population. There was observed a lack of awareness about oral diseases and poor accessibility for oral health provision, possible causes may be poor education status, poor socioeconomic status, rural background and cultural status. In this region, neither the patients were themselves aware nor the referral i.e. any oral health services provider made them aware about the disease being present at an earlier stage. Also the limitation of the present investigation is that the etiological factors and risk factors have not been looked into as retrospective records were used as a source for data analysis.

The key to an informed and motivated public lies in the hands of the profession, as well as the authorities. Health promotion, with its key concepts of equity and equality, empowerment and advocacy, offers a new and often complex approach to improving both general and oral health. It shifts the responsibility for health from the formal health care system to individuals, communities and decision- makers at all levels of society.

Further studies are required to identify the factors which different patients believe are relevant to their personal decision whether to seek periodontal treatment.

\section{Acknowledgements: None}

\section{Conflict of interest: None}

\section{References}

1. Manjunath, B.C.; Praveen, K.; Chandrashekhar, B.R. Periodontal infections: A risk factor for various systemic diseases. Natl Med J India 2011,24,214-19.

2. Saini, R. A Prospective Experimental Comparative Study on the Clinical Effects of Calculus Dissolution based Oral Rinse in Gingivitis Patients. Int J Experiment Dent Sci 2015,4(1),33-39.

3. Brunsvold, M.A.; Nair, P.; Oates, T.W. Jr. Chief complaints of patients seeking treatment for periodontitis. J Am Dent Assoc 1999,130,359-64.

4. Dementriou, N.; Parashis, A.; Tsami-Pandi, A. Relationship between age and clinical symptoms of periodontal disease. Stomatologia (Athenai) 1990,47,23141.

5. Burt B. Research, Science and Therapy Committee of the American Academy of Periodontology. Position paper: epidemiology of periodontal diseases. J Periodontol 2005,76,1406-19.

6. Hyde, S.; Satariano, W.A.; Weintraub, J.A. Welfare dental intervention improves employment and quality of life. J Dent Res 2006,85,79-84.

7. Lai, H.; Lo, M.T.; Wang, P.E.; Wang, T.T.; Chen, T.H.H.; Wu, G.H.M. A community-based epidemiological study of periodontal disease in Keelung, Taiwan: a model from keelung community- based integrated screening programme. J Clin Periodontol 2007,34,851-9.

8. Albandar, J.M. Periodontal diseases in North America. Periodontol 2000 2002,29,31-69.

9. Cobb, C.M.; Carrara, A.; El-Annan, E.; Youngblood, L.A.; Becker, B.E.; Becker W. Periodontal referral patterns, 1980 versus 2000: a preliminary study. J Periodontol 2003,74,1470-4.

10. Dye, B.A.; Thornton-Evans, G. A brief history of national surveillance efforts for periodontal disease in the United State. J Periodontol 2007,78,1373-9.

11. Loe, H.; Anerud, A.; Boysen, H. The natural history of periodontal disease in man: prevalence, severity, and extent of gingival recession. J Periodontol 1992,63,48995.

12. Yeh, H.C.; Lai, H. Association between patient's chief complaints and their compliance with periodontal therapy. J Clin Periodontol 2011,38,449-56.

13. Mehta, F.S. Relative importance of various causes of teeth loss. J All India Dent Assoc1958,30,211-21.

14. Peter, S. Epidemiology, Etiology \& Prevention of Periodontal Diseases. Peter S, editor. Essentials of Preventive and Community Dentistry, $3^{\text {rd }}$ edn. Arya (Medi) Publishing House, New Delhi, 2006, pp. 405-431.

15. Fardal, O.; Johannessen, A.C.; Linden, G.J. Pre-treatment conceptions of periodontal disease and treatment in periodontal referrals. J Clin Periodontol 2001,28,790-5.

16. Albandar, J.M. A 6-year study on the pattern of periodontal disease progression. J Clin Periodontol 1990,17,467-71.

17. Flemmig, T.F. Periodontitis. Ann Periodontol 1999,4,328 .

18. Baehni, P.; Giovannoli, J.L. Patient profile and decisionmaking in periodontal practice. Periodontol 2000 2004,36,27-34.

19. Carranza, F.A.; Takei, H.H. Clinical Diagnosis. In: Newman MG, Takei HH, Klokkevold PR, Carranza FA, editors. Carranza's Clinical Periodontology, $10^{\text {th }}$ edn. St. Louis, Missouri: Elsevier, 2007 pp,540-60.

20. Vered, Y.; Sgan-Cohen, H.D. Self - perceived and clinically diagnosed dental and periodontal health status 
among young adults and their implications for epidemiological surveys. BMC Oral Health 2003,3,3.

21. Merin, L. Supportive Periodontal Treatment. In: Newman MG, Takei HH, Klokkevold PR, Carranza FA, editors. Carranza's Clinical Periodontology, $10^{\text {th }}$ edn. St. Louis, Missouri, Elsevier; 2007, pp,1194-1205. 